\title{
A IMPORTÂNCIA DA ANÁLISE DE ESPECIAÇÃO DO CHUMBO EM PLASMA PARA A AVALIAÇÃo DOS RISCOS À SAÚDE
}

\author{
Fátima R. Moreira * e Josino C. Moreira
}

Centro de Estudos da Saúde do Trabalhador e Ecologia Humana, Escola Nacional de Saúde Pública, Fundação Oswaldo Cruz, Av. Leopoldo Bulhões, 1480, 21041-210 Rio de Janeiro - RJ

Recebido em 6/12/02; aceito em 6/11/03

\begin{abstract}
THE SIGNIFICANCE OF LEAD SPECIATION ANALYSIS IN BLOOD PLASMA FOR HEALTH RISK ASSESSMENT. Lead absorption is influenced by the species that are formed and the physicochemical characteristics of lead, among others. Lead plasma concentration is $\leq 5 \%$ of total blood lead and represents the biologically active fraction able to cross the cell membranes. Health risks mainly depend on a specific metal and its species. Speciation analysis is the analytical activity of identifying and determining different metal species. Chromatographic methods are very useful in the identification of species and the techniques most used to determine metals in biological fluids are ICP OES/MS and AAS. Lead speciation analysis in blood plasma is fundamental for understanding and evaluating the interaction mechanisms between that analyte and its biological targets.
\end{abstract}

Keywords: lead; plasma; speciation analysis.

\section{INTRODUÇÃO}

O interesse sobre acumulação e toxicidade de metais tem crescido nos últimos anos como conseqüência das exposições ocupacionais e ambientais, ou dos distúrbios causados por estes elementos, induzidos por situações especiais de doença como, por exemplo, a deficiência renal em fase terminal ${ }^{1}$.

O chumbo $(\mathrm{Pb})$ é um dos contaminantes mais comuns do ambiente, considerado como um elemento que possui efeitos tóxicos sobre os homens e animais, e sem nenhuma função fisiológica no organismo $^{2}$. Os efeitos nocivos do $\mathrm{Pb}$ são conhecidos desde os tempos antigos, já que este metal afeta praticamente todos os órgãos e sistemas do corpo humano. Apesar do osso conter aproximadamente $95 \%$ do conteúdo corpóreo total do metal em adultos, os primeiros efeitos adversos são vistos no sistema nervoso central e, ocasionalmente, na medula óssea, que são os órgãos críticos para este metal ${ }^{3}$.

A concentração de chumbo no sangue $(\mathrm{Pb}-\mathrm{S})$ é menor do que $2 \%$ do seu total no corpo. Deste valor, uma porção igual ou menor do que 5\% situa-se no plasma, representando a fração lábil e biologicamente ativa do chumbo, capaz de atravessar algumas barreiras anatômicas como, por exemplo, a barreira placentária e alcançar os tecidos fetais, causando danos irreversíveis ${ }^{4-6}$.

A concentração de chumbo no sangue é aceita como um indicador válido de exposição total ao chumbo e, conseqüentemente, de risco à saúde. Entretanto, reflete exposição ambiental recente, enquanto que o conteúdo de chumbo no osso $(\mathrm{Pb}-\mathrm{O})$ reflete exposição acumulada. $\mathrm{O} \mathrm{Pb}-\mathrm{O}$ tem uma relação mais direta com os níveis de chumbo plasmático do que no sangue total, o que significa que $\mathrm{Pb}-\mathrm{S}$ pode não representar adequadamente os teores deste elemento no plasma ${ }^{7}$.

Embora o conhecimento do conteúdo total do metal numa dada amostra seja útil nos programas de monitoramento ambiental e ocupacional, é insuficiente para a compreensão do metabolismo, a elucidação dos mecanismos de toxicidade, o entendimento do modo de entrada e/ou distribuição do elemento na célula, ou os estudos das interações dos diferentes metais em relação à ligação com proteínas e deposição nos tecidos ${ }^{8}$. Estes aspectos dependem da especiação,

*e-mail: fmoreira@ensp.fiocruz.br que é a ocorrência de um elemento em diferentes formas. Portanto, a análise de especiação, ou seja, a identificação e determinação dos constituintes que se ligam e/ou que transportam o analito de interesse é essencial.

A maioria das metodologias descritas na literatura é pouco específica, está sujeita à contaminação, ou não pode ser usada em amostras, cujas concentrações sejam de importância clínica. Por isso, os dados publicados até agora sobre especiação e ligação dos metais traço com proteínas são contraditórios e devem ser interpretados com cautela ${ }^{1}$.

Uma revisão da literatura mostra que o cromo é o metal mais investigado pela maioria dos pesquisadores. É evidente a preferência pela análise de especiação em águas naturais, seguida de materiais biológicos. Há também muitos relatos sobre a especiação em solos e sedimentos, enquanto que são poucas as publicações em material particulado?.

A literatura sobre a especiação de metais em fluidos biológicos é limitada, visto que uma revisão do assunto revela que a maioria dos trabalhos tem sido realizada em sangue, urina e leite. O trabalho sobre análise de especiação de metais em fluidos biológicos é incompleto, devido à ausência de experimentos com um grande número de elementos importantes (V, Mo, Ni, B) e aos poucos estudos desenvolvidos em alguns fluidos biológicos de grande interesse ${ }^{10}$. Os níveis de chumbo no plasma raramente têm sido medidos por causa de dificuldades analíticas e, por isso, sua relação com as manifestações tóxicas não é clara" ${ }^{11}$.

Assim, esta continua sendo uma área de pesquisa fundamental ao entendimento dos mecanismos de interação e toxicidade dos metais e, portanto, muito promissora.

\section{CHUMBO E SUAS CARACTERÍSTICAS}

\section{Propriedades químicas e físicas}

O chumbo juntamente com o carbono, o silício, o germânio e o estanho formam o grupo 14 da tabela periódica. É encontrado no seu estado natural em depósitos minerais, de onde são extraídos de 3 a $10 \%$ de $\mathrm{Pb}$. É um metal pesado de cor cinza azulada, com número atômico igual a 82, e massa atômica relativa e densidade iguais a 
207,2 unidades de massa atômica ( 1 uma $=1,6605402 \times 10^{-27} \mathrm{~kg}$ ) e $11340 \mathrm{~kg} \mathrm{~m}^{-3}$, respectivamente. Seu ponto de fusão é a $327,4{ }^{\circ} \mathrm{C}$, enquanto o de ebulição se encontra a $1749{ }^{\circ} \mathrm{C}$. O chumbo fundido produz fumos em quantidades mensuráveis a partir de temperaturas entre 500 e $600{ }^{\circ} \mathrm{C}$, que combinados com o oxigênio do ar formam o óxido de chumbo. A evaporação aumenta com a elevação da temperatura. Este metal é macio e maleável, e contrai-se consideravelmente sob resfriamento. O chumbo elementar é pouco solúvel em água e ácidos diluídos, porém se dissolve nos ácidos nítrico, acético e sulfúrico concentrado quente 12-14 $^{\text {. }}$

Embora o chumbo tenha quatro elétrons na sua camada de valência, somente dois ionizam-se facilmente. Por isso, o estado de oxidação comum para o chumbo em compostos inorgânicos é +2 ao invés de +4. Dos compostos normalmente encontrados, o acetato e o nitrato são facilmente solúveis em água fria, enquanto que os cloretos, cromatos e estearatos são moderadamente solúveis. Já a solubilidade de compostos, tais como carbonato, óxido, sulfato e sulfeto, é baixa. Sob condições apropriadas de síntese, o chumbo também forma compostos orgânicos estáveis, sendo o tetraetil e o tetrametil chumbo os mais importantes pelo uso como aditivos para combustível. São ligeiramente voláteis e praticamente insolúveis em água, mas dissolvem-se rapidamente em solventes orgânicos, gorduras e lipídeos ${ }^{13,14}$.

\section{Ocorrência natural e usos}

O chumbo é um elemento de ocorrência natural, que vem sendo usado praticamente desde o início da civilização. Atualmente, este metal é onipresente no ambiente, devido às inúmeras atividades industriais que favorecem sua ampla distribuição. Todos os seres humanos têm chumbo em seus organismos, originalmente como um resultado de exposição às fontes exógenas. Depósitos naturais de chumbo ocorrem em todo o mundo, sendo que a galena $(\mathrm{PbS})$ é o minério mais abundante e de onde é extraída a maior parte do chumbo obtido comercialmente ${ }^{15}$. Devido ao seu baixo ponto de fusão e à facilidade de trabalho, este metal tem sido transformado em uma enorme variedade de objetos e utensílios, tais como munição, canos, tipos para impressão, proteção radiológica, folhas de chumbo, produtos de latão e bronze, entre outros. Além disso, ele tem sido usado de várias formas, como pigmento em tintas, verniz para cerâmicas, soldas, aditivos anti-detonantes em combustíveis, etc. É o metal não ferroso mais amplamente utilizado, sendo que, até o início da década de $90,52 \%$ era usado em baterias de armazenamento e como antidetonantes, e aproximadamente $48 \%$ em proteção de cabos, pigmentos, ligas, instalações resistentes a ácidos, cristais, cerâmicas vitrificadas e estabilizantes para plásticos e borrachas ${ }^{5}$.

\section{Fontes de exposição humana e ambiental}

A maior parte do chumbo utilizado pela indústria vem da exploração de minérios ("primária") ou da reciclagem de fragmentos de metal ou baterias ("secundária"). As atividades humanas têm espalhado o chumbo por todo o ambiente ${ }^{14}$. Atualmente, as maiores fontes ambientais de chumbo e seus sais, que contribuem para a ingestão diária, são ar, poeira, alimentos, bebidas e tinta. A fumaça de cigarro também pode aumentar o total de chumbo ingerido por dia. Alimentos tais como frutas, vegetais, carnes, grãos, frutos do mar, bebidas suaves e vinhos podem conter chumbo, originado da água de preparo, plantas e animais criados em locais contaminados. Potes ou pratos de cerâmica vitrificados incorretamente, vidraria de cristal contendo chumbo, latas e chaleiras com solda à base do metal também contribuem para a contaminação da alimentação ${ }^{7}$.

A ingestão de tintas que contêm chumbo se constitui na maior fonte disponível do metal para crianças e importante fonte para mui- tos adultos, especialmente aqueles envolvidos com construção e reforma de casas, e os que têm a pintura como profissão ou passatempo. Outras fontes também podem aumentar o total de chumbo ingerido por dia, tais como brinquedos pintados, cosméticos faciais, tintura de cabelo, impressão colorida, água de tubulação com solda de chumbo e os remédios populares ${ }^{15}$.

Embora a combustão da gasolina com alquil- $\mathrm{Pb}$ já tenha sido fonte primária de poluição do ar, as emissões industriais deste elemento, tais como fundições de metais não ferrosos, fábricas de baterias, plantas químicas e modificação de construções antigas contendo tinta à base de chumbo são agora os maiores contribuintes para o total do metal liberado para a atmosfera ${ }^{5}$.

O chumbo da gasolina, tintas e produtos cerâmicos, calefação e soldas tem sido drasticamente reduzido devido às preocupações com a saúde e o meio ambiente. Este elemento também tem sido identificado em uma enorme variedade de ambientes (ar, água de superfície, lençóis d'água, chorume, solo, sedimento, peixes e animais de caça) coletados nos perigosos depósitos de lixo, onde freqüentemente é o metal mais encontrado ${ }^{14}$.

\section{O problema da contaminação pelo chumbo}

Os países desenvolvidos têm conseguido reduzir o uso de chumbo nos últimos anos, principalmente através de programas de prevenção da exposição, de modo que a concentração deste metal no sangue da população diminuiu drasticamente nos últimos 20 anos, chegando a $78 \%$ nos EUA. Já nos países em desenvolvimento, o chumbo continua a ser um importante problema de saúde pública, com várias formas de exposição. Na América Latina, a exposição através das cerâmicas possui dimensões consideráveis e, especialmente, para a população pobre, diferentes fontes de exposição, tais como mineração, fábricas de baterias, artesanato e fundições, são mais importante do que o petróleo ${ }^{16}$. Romieu e colaboradores revelaram que, na América Latina, a média das concentrações de chumbo no sangue de crianças excedeu $10 \mu \mathrm{g} \mathrm{dL}^{-1}$, nível determinado pelo "Center of Disease Control" (CDC) para crianças, na maioria dos países investigados. Cerca de $75 \%$ era de zona urbana e 30\%, menores de 15 anos de idade, indicando que as crianças continuam a ser alvo de altos níveis de exposição ${ }^{17}$.

No Brasil, como nos outros países em desenvolvimento, o controle e a prevenção da exposição ao chumbo é praticamente inexistente. Embora não existam dados sistematizados sobre as ocorrências de contaminação por este metal, as poucas informações disponíveis permitem supor que sejam relativamente elevadas. Em 1987, na Grande Belo Horizonte, MG, 52\% dos trabalhadores de uma indústria de acumuladores elétricos encontravam-se intoxicados por chumbo. Também os operários da maior fábrica de acumuladores elétricos da cidade de Campinas, SP, estavam contaminados por este elemento em 1989. Já em Bauru, SP, foram identificados 800 casos de saturnismo em trabalhadores de duas indústrias de acumuladores elétricos entre 1985 e $1987^{18}$. Entretanto, somente em 2002 a justiça suspendeu as atividades de uma destas indústrias, depois de comprovada contaminação por chumbo no solo, vegetação, animais e também em crianças, nas proximidades da empresa ${ }^{19}$.

Em 2001, foi demonstrada a contaminação da população e do ambiente por chumbo nas circunvizinhanças a três mineradoras, que atuaram no beneficiamento e refino dos minérios de chumbo produzidos nas jazidas da região da Bacia do Rio Ribeira de Iguape entre 1920 e 1996, uma das regiões mais pobres dos estados de São Paulo e Paraná. Altas concentrações de chumbo foram encontradas nos solos das áreas ao redor das usinas, nos sedimentos e peixes do rio e, também, em crianças de localidades próximas às minerações ${ }^{20}$.

O processo metalúrgico empregado durante o período de produ- 
ção (1960-1993) de ligas e escórias de chumbo por uma usina metalúrgica em Santo Amaro da Purificação, BA, resultou em forte contaminação da população e do meio ambiente, através do material particulado expelido pela chaminé, efluentes líquidos despejados diretamente no rio Subaé e transbordamento da bacia de rejeito, e das águas de drenagem da área de armazenamento da escória ${ }^{21}$. Em 2001, um relatório da Secretaria de Saúde de Paulínia, SP, sobre os exames médicos de 181 moradores do bairro Recanto dos Pássaros, contaminado pela Shell Química do Brasil, indicou que 60 moradores apresentaram chumbo em níveis preocupantes ${ }^{22}$.

A Fundação Instituto de Tecnologia de Pernambuco realizou, em agosto de 1991, exames laboratoriais em 51 operários de duas empresas que trabalham com fabricação e reciclagem de baterias automotivas, pertencentes a um mesmo grupo, e constatou que $63 \%$ dos examina-

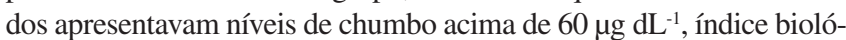
gico máximo permitido (IBMP) pela Norma Regulamentadora $n^{\circ} 7$ (NR 7), Portaria n 24/1994 do Ministério do Trabalho. Em novembro de 1992, a Fundacentro-PE relatou que a maioria dos setores destas empresas apresentava concentrações de chumbo no ar superiores ao limite de tolerância $\left(0,1 \mathrm{mg} \mathrm{m}^{-3}\right)$ estabelecido pela legislação trabalhista brasileira. O Greenpeace realizou um levantamento preliminar do grau de contaminação por chumbo em Belo Jardim, PE, área de influência destas empresas, em setembro de 1996. As análises de águas, sedimentos e solos adjacentes às fábricas apontaram a presença de níveis extremamente elevados de chumbo na região amostrada. A Resolução do Conama 20/86 define que o nível máximo de chumbo permitido em efluentes líquidos industriais tratados, antes de serem lançados nos corpos hídricos receptores, é de $0,05 \mathrm{mg} \mathrm{L}^{-1}$. Entretanto, a legislação brasileira não estabelece limites máximos aceitáveis para chumbo em sedimentos ou solos ${ }^{23}$.

No Rio de Janeiro, um projeto multidisciplinar avaliou a exposição ao chumbo em trabalhadores de fábricas e reformadoras de baterias e da população circunvizinha às mesmas. Esta avaliação mostrou que todas as empresas ofereciam risco à saúde dos funcionários, conforme os resultados obtidos através do monitoramento biológico e do ar interno, e dos exames clínicos. Apesar da maioria das amostras coletadas a uma distância de até $25 \mathrm{~m}$ de uma das reformadoras ter excedido o limite de $1,5 \mu \mathrm{g} \mathrm{Pb} \mathrm{m}^{-3}$, estabelecido pela "Environmental Protect Agency" (EPA) ${ }^{24}$, a população circunvizinha não se mostrou contaminada, com níveis de $\mathrm{Pb}$ no sangue menores do que $10 \mu \mathrm{g} \mathrm{L}^{-1}$

Os índices biológicos máximos permitidos para chumbo na NR 7 são os mesmos fixados pela "American Conference of Governmental Industrial Hygienists" (ACGIH) nos Estados Unidos em 1972, baseados no conhecimento científico vigente na época. Entretanto, a ocorrência de alterações nervosas em trabalhadores expostos ocupacionalmente ao chumbo tem sido descrita em níveis abaixo do IBMP brasileiro. Resultados de estudos sustentam a redução do atual valor para $32 \mu \mathrm{g} \mathrm{dL}^{-1}$ no nosso meio ${ }^{25}$, o que é compatível com o índice biológico de exposição de $30 \mu \mathrm{g} \mathrm{dL}^{-1}$ para chumbo em sangue, recomendado pela ACGIH em 1998. Entretanto, foi observado que o comitê deveria reavaliar este valor na medida em que novos dados estivessem disponíveis ${ }^{26}$.

Também o limite de tolerância para chumbo no ar, $0,1 \mathrm{mg} \mathrm{m}^{-3}$, estabelecido pela Norma Regulamentadora ${ }^{\circ} 15$ (NR 15), Portaria $\mathrm{n}^{\mathrm{o}}$ 12/1983 do Ministério do Trabalho ${ }^{27}$, é o dobro daquele preconizado pela ACGIH, $0,05 \mathrm{mg} \mathrm{m}^{-3}$, para que a maioria dos trabalhadores possa ser exposta, sem efeitos adversos, durante um dia normal de $8 \mathrm{~h}$ de trabalho ${ }^{5}$

\section{Cinética}

No organismo humano, o chumbo é complexado por macromolé- culas, sendo diretamente absorvido, distribuído e excretado. A inalação (importante rota na exposição ocupacional) e a ingestão (via predominante para a população em geral) são os principais modos de entrada deste metal no organismo. Somente os compostos orgânicos de chumbo penetram ao contato com a pele íntegra, sendo absorvidos rapidamente ${ }^{6}$.

A absorção do chumbo é influenciada pela rota de exposição, forma química, tamanho da partícula, bem como pela solubilidade dos compostos deste metal, e variações individuais fisiológicas e patológicas. Pode ser superior a 50\%, no caso da inalação de gases de exaustão de motores e de sais altamente solúveis, assim como nos fumantes e pessoas sofrendo de doenças agudas e crônicas das vias respiratórias superiores ${ }^{14}$.

A absorção do chumbo no trato gastrointestinal pode chegar a $80 \%$, se ingerido em jejum. Mulheres grávidas e crianças absorvem 45 a $50 \%$ do chumbo proveniente da $\operatorname{dieta}^{28}$. Os fatores da nutrição, tais como estado fortificado, ingestão de cálcio, ferro, fósforo e proteínas, são mais importantes para a absorção do metal por esta via do que a solubilidade dos compostos de chumbo, devido à acidez estomacal. A deficiência destes nutrientes aumenta a absorção do chumbo e vice-versa ${ }^{29}$.

A distribuição do chumbo no organismo depende da sua taxa de transferência da corrente sangüínea para os diferentes órgãos e tecidos. Uma vez absorvido, o chumbo segue uma cinética complexa no organismo, cujo modelo metabólico ainda não foi estabelecido. Por isso, um modelo ${ }^{30}$ de três compartimentos (Figura 1) - sangue, tecidos moles (rins, medula óssea, fígado e cérebro) e tecidos mineralizados (ossos e dentes) - tem sido muito utilizado. Os ossos contêm cerca de 90 a $95 \%$ do total do conteúdo corpóreo de chumbo em adultos e de 80 a $95 \%$ em crianças $^{31}$. O chumbo tem tempos de meiavida distintos nos três depósitos, sendo que a meia-vida no sangue é de 36 dias. Já o chumbo nos tecidos moles tem uma meia-vida de aproximadamente 40 dias, enquanto que nos ossos, este tempo é de cerca de 27 anos 7 .

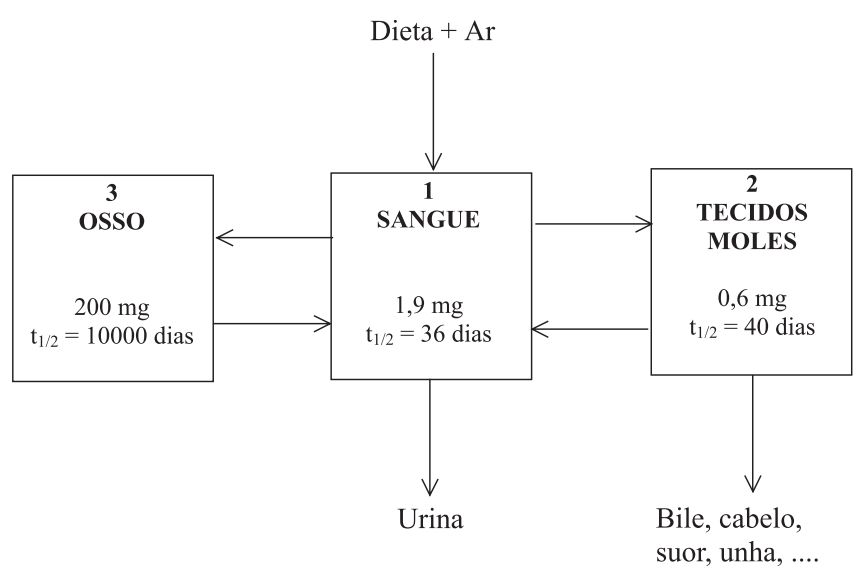

Figura 1. Modelo de três compartimentos para o metabolismo do chumbo. Conteúdo e tempo de meia-vida de $\mathrm{Pb}$ em cada reservatório

De acordo com os resultados de estudos isotópicos sobre a liberação do $\mathrm{Pb}$ do osso para a circulação, o esqueleto contribui com 40 a $70 \%$ do chumbo presente no sangue de indivíduos expostos ambientalmente, embora esta concentração $(\mathrm{Pb}-\mathrm{S})$ seja menor do que $2 \%$ do seu total no corpo ${ }^{32}$. Neste compartimento, de $90-99,8 \%$ do $\mathrm{Pb}$ está ligado às membranas ou frações de proteínas das células vermelhas e cerca de 0,2 a $10 \%$ do $\mathrm{Pb}-\mathrm{S}$ está no plasma, provavelmente ligado à albumina, $\alpha_{2}$-globulina ou como íons livres disponíveis para o transporte para os tecidos. É possível que esta última fração tenha maior importância toxicológica do que o chumbo nos 
eritrócitos, por estar mais biodisponível para atingir os sítios-alvo da ação toxicológica ${ }^{33}$.

A determinação do chumbo no plasma é uma medida mais exata do que no sangue para avaliação da exposição, especialmente em níveis elevados do metal, uma vez que este componente do sangue contém o $\mathrm{Pb}$ livre para cruzar as membranas celulares e causar seus efeitos tóxicos ${ }^{11}$. Os ligantes presentes no plasma, e disponíveis para a ligação com o $\mathrm{Pb}$, ainda não estão bem definidos, mas tem sido sugerida a existência de frações difusíveis de chumbo em equilíbrio com sítios ativos de órgãos-alvo e tecidos moles e, também, com as células vermelhas. As concentrações plasmáticas de chumbo raramente têm sido medidas devido às dificuldades analíticas e, por isso, sua relação com as manifestações tóxicas não está claramente definida $^{4,33}$.

Após entrar no sangue, o chumbo é distribuído entre os órgãos, dependendo do gradiente de concentração e da afinidade com o tecido específico. Os níveis mais altos têm sido encontrados na aorta, fígado, rins, pulmões e cérebro. A retenção do chumbo nos tecidos moles estabiliza-se na vida adulta e pode decrescer em alguns órgãos com a idade. Entretanto, este metal continua a se acumular nos ossos e na aorta durante toda a vida ${ }^{6}$. O chumbo atravessa a barreira hemato-encefálica, mas sua concentração no cérebro é baixa ${ }^{34}$. Ele também penetra na placenta, e o sangue fetal contém quase que os mesmos níveis do metal que o sangue materno ${ }^{35}$.

Durante sua distribuição, o chumbo segue o caminho metabólico do cálcio e acumula-se nos ossos e dentes ${ }^{36}$. Estes grandes depósitos servem para manter os níveis de chumbo no sangue após o término da exposição e, também, como fonte deste metal para a produção do esqueleto fetal ${ }^{37}$. O reconhecimento do osso como um órgão dinâmico tem levantado interesse de que o $\mathrm{Pb}$ aí estocado pode ser mobilizado para a circulação sangüínea, proporcionando um mecanismo para a toxicidade tardia. Este fenômeno foi sugerido por inúmeros estudos sobre estados fisiológicos e patológicos, conhecidos por serem acompanhados de elevadas renovações ósseas ${ }^{38-39}$, tais como o rápido crescimento de $\operatorname{crianças~}^{40}$, gravidez ${ }^{41}$, lactação ${ }^{42}$, osteoporose $^{43}$ e menopausa ${ }^{44}$. No entanto, uma pesquisa mostrou que o uso da terapia de reposição hormonal pode reduzir a mobilização do $\mathrm{Pb}$ endógeno para o sangue ${ }^{45}$. Em distúrbios no equilíbrio ácidobase, infecções, intervenções cirúrgicas e terapias com certas drogas, ou quando há remoção da exposição, como no caso de licença médica ou aposentadoria, o chumbo também pode ser inesperadamente mobilizado, levando à aparição de sintomas tóxicos, mesmo após cessada a exposição ${ }^{46}$.

A macrodistribuição do chumbo dentro do sistema ósseo é claramente dependente do tipo de osso (cortical ou trabecular), sendo o osso trabecular uma importante fonte do metal reabsorvido, quando há redução da exposição ${ }^{7}$. As interações entre o chumbo e o metabolismo do cálcio podem controlar a toxicidade desse elemento em mulheres ao longo de suas vidas ${ }^{38}$, uma vez que a distribuição do chumbo nos ossos também depende da idade e, em menor grau, do gênero ${ }^{47}$.

O chumbo é excretado por várias rotas, porém só a excreção renal e a gastrointestinal são de importância prática. A quantidade excretada, independente da rota, é afetada pela idade, características da exposição e dependente da espécie ${ }^{5}$. A determinação da concentração do chumbo na urina tem sido usada como teste de exposição em saúde ocupacional, já que reflete uma exposição atual ${ }^{14}$. Experimentos realizados com trabalhadores expostos ocupacionalmente encontraram correlações muito próximas entre o nível de chumbo no sangue e ossos e sua excreção urinária, usando ácido 2,3 mesodimercaptosuccínico (DMSA) e ácido etilenodiamino tetracético (EDTA) como agentes quelantes ${ }^{48}$.

O chumbo absorvido é excretado principalmente pela urina (75$80 \%$ ), cerca de $15 \%$ pelas fezes, e outras possíveis rotas de elimina- ção são suor, descamação cutânea, cabelo e unhas $(<8 \%)^{10}$. Uma forma especial de excreção do chumbo endógeno, mas de pouca importância do ponto de vista de liberação do organismo, é através do leite materno. No entanto, este tipo de eliminação pode representar um risco para o lactente, já que existe uma correlação entre as concentrações do chumbo no sangue e leite. Baixos níveis de chumbo têm sido encontrados no sêmen de homens sem exposição específica. Os níveis de chumbo no fluido seminal de trabalhadores expostos são, aproximadamente, um décimo daqueles encontrados no sangue ${ }^{34,49}$.

De modo geral, o chumbo é excretado de forma extremamente lenta. Sua meia-vida biológica exata não é conhecida, porém pode ser da ordem de 10 anos para homens. Como a excreção é lenta, a acumulação acontece facilmente. Conseqüentemente, após uma única exposição, o nível de chumbo no sangue de uma pessoa pode começar a retornar ao normal, entretanto, o conteúdo corpóreo total pode ainda ser elevado ${ }^{14}$.

Grandes exposições agudas não precisam ocorrer para que um envenenamento por chumbo se desenvolva. $\mathrm{O}$ corpo acumula este metal durante toda a vida e o libera lentamente, de modo que mesmo doses pequenas, por pouco tempo, podem causar intoxicação. O conteúdo total de chumbo no corpo é que está relacionado com o risco de efeitos adversos ${ }^{15}$.

\section{Efeitos nos seres humanos}

Os metais pesados podem danificar qualquer atividade biológica existente e, por isso, há, teoricamente, tantos tipos de respostas quantas forem as atividades. No entanto, certos tipos de resposta predominam por haver grande variedade de acesso dos componentes biológicos aos órgãos, tecidos, células e moléculas. Por exemplo, todos os sistemas enzimáticos são potencialmente suscetíveis aos metais pesados, que, num organismo vivo, podem ter sua entrada limitada pelas estruturas anatômicas; sítios ligantes inertes podem competir pelo íon metálico. Por estas razões, freqüentemente existem consideráveis diferenças em sensibilidade entre diferentes órgãos e tecidos, na ação observada entre experimentos in vivo e in vitro, entre espécies e em certas respostas típicas para envenenamento clínico ${ }^{14}$.

O chumbo é um elemento tóxico não essencial que acumula no organismo. Na sua interação com a matéria viva, o chumbo apresenta características dos metais pesados e algumas peculiaridades. Como este metal afeta virtualmente todos os órgãos e sistemas do organismo, os mecanismos de toxicidade propostos envolvem processos bioquímicos fundamentais, que incluem a capacidade do chumbo de inibir ou imitar a ação do cálcio e interagir com proteínas. Em níveis de exposição moderada, um importante aspecto dos efeitos tóxicos deste metal é a reversibilidade das mudanças bioquímicas e funcionais induzidas. Esses efeitos são principalmente devidos à interferência do chumbo no funcionamento das membranas celulares e enzimas, formando complexos estáveis com ligantes contendo enxofre, fósforo, nitrogênio ou oxigênio (grupamentos $-\mathrm{SH},-\mathrm{H}_{2} \mathrm{Po}_{3}$, $\left.\mathrm{NH}_{2},-\mathrm{OH}\right)$ como doadores de elétrons ${ }^{5}$. As interações bioquímicas do chumbo com grupamentos -SH são consideradas de grande significado toxicológico, visto que, se isto ocorre numa enzima, sua função pode ser inibida, resultando em efeitos tóxicos. O chumbo também tem uma alta afinidade por aminas e amino-ácidos simples ${ }^{6}$.

Em geral, estas ligações dos íons $\mathrm{Pb}^{2+}$ com o material bioquímico são fortes, porém um tanto inespecíficas. A estabilidade dos complexos de chumbo aumenta com o número crescente de sítios ligantes, e com espaçamentos ótimos, tais como com grupamentos sulfidrilas vicinais. A capacidade do chumbo em mimetizar o cálcio na ativação da calmodulina envolve ligação com grupos carboxilas, enquan- 
to que os sulfidrilas estão relacionados com a ativação da proteína quinase $\mathrm{C}^{5}$.

O chumbo induz a mudanças nos eletrólitos do sangue ( $\mathrm{Na}, \mathrm{K}$, $\mathrm{Ca}, \mathrm{P})$, no metabolismo mineral ( $\mathrm{Zn}, \mathrm{Cu}, \mathrm{Mn}, \mathrm{Al}, \mathrm{Si}$ ) de carboidratos e de lipídeos (com inibição das enzimas contendo -SH), no metabolismo da síntese de proteínas, DNA e RNA, na utilização de vitaminas $\left(\mathrm{B}_{1}, \mathrm{PP}, \mathrm{B}_{12}, \mathrm{C}\right)$, na produção de certos hormônios, no metabolismo de amino-ácidos, etc. Essas mudanças são consideradas não específicas somente com respeito aos efeitos do chumbo e até agora não têm sido aplicadas no monitoramento biológico ${ }^{6}$.

Os efeitos biológicos do chumbo são os mesmos quaisquer que sejam as rotas de entrada (inalação ou ingestão), uma vez que há interferência no funcionamento normal da célula e em inúmeros processos fisiológicos ${ }^{14}$. Apesar dos ossos serem os maiores depósitos de chumbo, as informações são limitadas com respeito ao seu efeito e potenciais mecanismos de ação sobre estes sítios ${ }^{15}$. Também os primeiros efeitos adversos não são observados nos ossos, e sim, no sistema nervoso, medula óssea e rins, tidos como órgãos críticos na exposição ao chumbo, enquanto que os distúrbios na função do sistema nervoso (SN) e os desvios na síntese do heme são considerados como efeitos tóxicos críticos ${ }^{34}$.

A Tabela 1 apresenta os principais efeitos sobre a saúde relacionados ao chumbo e seus respectivos órgãos críticos.

\section{MONITORAMENTO BIOLÓGICO NA AVALIAÇÃO DOS RISCOS À SAÚDE}

A avaliação dos riscos à saúde determina a relação entre a exposição e os efeitos adversos. A identificação do perigo, avaliação de dose-resposta, avaliação da exposição e caracterização do risco são as principais etapas envolvidas neste processo. A avaliação da exposição é a medida da concentração de uma substância química presente no ambiente (monitoramento ambiental) e/ou no organismo (monitoramento biológico). Rotas comuns de exposição são ingestão, inalação, absorção através da pele e injeção (menos provável) ${ }^{62}$.

O monitoramento biológico (MB) consiste na medida e quantificação de um metal em vários meios biológicos, tais como sangue, urina, fezes, cabelo ou leite materno, para avaliar a exposição e riscos à saúde, e sua comparação com referências apropriadas, que são os limites biológicos de exposição. Uma vez que muitos metais permanecem no organismo por um tempo considerável após a exposi- ção, o MB pode fornecer informações sobre exposições ocorridas no passado $^{63}$.

\section{Monitoramento biológico do chumbo}

Atualmente, existem inúmeros testes que mostram a ocorrência de exposição ao chumbo. O metal pode ser determinado em sangue, tecidos moles, ossos e dentes, através de indicadores de dose interna e de efeito, tais como sangue total, plasma e urina, e ácido delta aminolevulínico na urina (ALA-U), ácido delta aminolevulínico desidratase (ALAD), zinco protoporfirina (ZPP) e protoporfirina eritrocitária (PE), respectivamente ${ }^{13}$. No entanto, todos têm algum tipo de limitação e, por isso, a concentração de chumbo no sangue total é aceita como indicador de exposição total a este elemento, apesar de indicar uma exposição recente.

$\mathrm{O}$ chumbo pode ser medido nos dentes e ossos, que refletem exposição de longo prazo, por fluorescência de raio-X (camadas $\mathrm{K}$ e L), porém este método ainda não está amplamente disponível. A acuracidade e precisão das medidas de chumbo no osso in vivo usando fluorescência de raios X de camada L (FRXL) foram comparadas com aquelas das medidas independentes de chumbo no osso, obtidas por espectrometria de absorção atômica eletrotérmica (ET AAS), após digestão ácida. A concordância entre FRXL e ET AAS foi razoavelmente boa para o osso exposto, mas pobre para a perna íntegra. A variabilidade das medidas por FRXL foi grande para ambas as amostras, o que gera sérias suspeitas sobre o seu uso analítico in $v i v o^{64}$. A protoporfirina eritrocitária é uma parte das células vermelhas que aumenta quando a quantidade de chumbo no sangue é elevada. Entretanto, não é sensível o suficiente para identificar níveis de chumbo, em torno de $25 \mu \mathrm{g} \mathrm{dL}{ }^{-1}$. Por isso, o método primário de rastreamento continua sendo a medida de chumbo no sangue ${ }^{4}$.

A determinação da concentração de chumbo no sangue ( $\mathrm{Pb}-\mathrm{S})$ é o biomarcador de exposição a este metal mais amplamente utilizado. É o teste de rastreamento e diagnóstico mais útil para esta exposição ${ }^{14}$. Contudo, uma única determinação de $\mathrm{Pb}-\mathrm{S}$ não pode distinguir entre exposição intermediária ou crônica de baixo nível e exposição aguda de nível elevado, devido à mobilização cíclica do chumbo entre o sangue e o osso. Os dois tipos de exposição poderiam resultar no mesmo nível de $\mathrm{Pb}-\mathrm{S}$ por causa da repetição do ciclo a partir do osso. Por isso, a concentração de chumbo em sangue não serve como medida exata da exposição ao metal ou do conteúdo

Tabela 1. Principais efeitos sobre a saúde relacionados ao chumbo e os respectivos órgãos críticos

\begin{tabular}{|c|c|c|c|}
\hline Efeitos sobre a saúde & Órgãos críticos & Efeitos adversos & Ref. \\
\hline Neurológicos & $\begin{array}{l}\text { Sistema nervoso central, } \\
\text { periférico e autônomo }\end{array}$ & Encefalopatia aguda e crônica; neuropatia periférica & $50-52$ \\
\hline Hematológicos & Sangue & Anemia & 53 \\
\hline Endócrinos & Tecidos ósseos e soro & $\begin{array}{l}\text { Prejuízo aos rins e ao desenvolvimento das células, dentes } \\
\text { e ossos. Possíveis danos à tireóide }\end{array}$ & 54 \\
\hline Crescimento & Ossos & Crescimento reduzido & 55 \\
\hline Renais & Rins & Nefropatia e gota saturnínica & 56,57 \\
\hline $\begin{array}{l}\text { Reprodutivos e de } \\
\text { Desenvolvimento }\end{array}$ & $\begin{array}{l}\text { Sistema reprodutor masculino } \\
\text { e feminino }\end{array}$ & $\begin{array}{l}\text { Fertilidade reduzida, grande probabilidade de abortos } \\
\text { espontâneos, contagem reduzida de esperma e motilidade; } \\
\text { teratogênico em animais }\end{array}$ & 35,58 \\
\hline Carcinogênicos & Rins e células do DNA genômico & $\begin{array}{l}\text { Carcinogênico para os animais e envolvimento epigenético } \\
\text { na expressão do gene alterado }\end{array}$ & 59 \\
\hline Cardiovasculares & Sistema cardiovascular & $\begin{array}{l}\text { Provável aumento na pressão sangüínea, lesões cardíacas e } \\
\text { eletrocardiogramas anormais }\end{array}$ & $51,57,60$ \\
\hline Gastrointestinais & Trato gastrointestinal & Cólica & $5,7,14,34$ \\
\hline Hepáticos & Fígado & $\begin{array}{l}\text { Capacidade funcional reduzida do citocromo P-450 para } \\
\text { metabolizar drogas }\end{array}$ & $4,7,34,61$ \\
\hline
\end{tabular}


corpóreo total do mesmo, devido aos processos interferentes de transferência, mobilização e armazenamento entre os diferentes compartimentos do corpo. Assim, o nível de chumbo no sangue reflete um equilíbrio dinâmico entre absorção, excreção e depósito nos compartimentos de tecidos moles e duros, enquanto que, para exposições crônicas, subestima o conteúdo corpóreo total ${ }^{6}$.

Aproximadamente $95 \%$ do chumbo no sangue estão ligados aos eritrócitos, não sendo, por isso, facilmente dispersados. $\mathrm{O}$ chumbo no plasma (5\% do conteúdo total do sangue) é composto de duas frações: uma ligada às proteínas do plasma e a outra, dispersa. Provavelmente, esta última fração é o centro metabolicamente ativo do depósito de chumbo no organismo e fornece a melhor aproximação do conteúdo de chumbo biologicamente efetivo ${ }^{13}$. Porém, a variação natural na partição relativa (\%) do chumbo entre sangue total e plasma é de 2 a 4 vezes para um determinado nível deste elemento no sangue total e reflete as diferenças inerentes aos indivíduos, contanto que técnicas limpas e sensíveis sejam usadas para coleta e análise das amostras, respectivamente ${ }^{65}$.

As baixas concentrações de chumbo no plasma fazem com que estas medidas sejam extremamente difíceis, particularmente em baixas concentrações de $\mathrm{Pb}-\mathrm{S}$ (menos de $20 \mu \mathrm{g} \mathrm{dL}^{-1}$ ). Entretanto, usando técnicas analíticas mais sensíveis, estudos recentes têm mostrado que as concentrações de chumbo no plasma podem se correlacionar mais fortemente com os níveis de chumbo no osso do que as concentrações de chumbo em sangue ${ }^{5}$.

\section{A ESPECIAÇÃO NO MONITORAMENTO BIOLÓGICO}

Até alguns anos, pensava-se que a determinação da concentração total de um metal seria suficiente para os propósitos clínicos e ambientais. Entretanto, a toxicidade é uma propriedade dependente da espécie e, assim, o conhecimento das concentrações relativas de todas as espécies químicas presentes em um determinado meio é muito mais relevante para avaliação da exposição do que sua concentração total $^{8,66}$.

A identificação e a quantificação de elementos são necessárias, porém não são suficientes, na maioria dos casos, para compreender e avaliar o mecanismo de interação entre elementos e alvos biológicos. Assim, a capacidade de separar, identificar e quantificar as diversas espécies químicas sob as quais o elemento de interesse está presente e/ou transformado em um determinado meio é o que se denomina de análise de especiação. Poucos, porém crescentes, são os exemplos de estudos de especiação química de elementos capazes de confirmar a importância deste tipo de pesquisa nos estudos toxicológicos. Algumas informações provenientes destes estudos encontraram aplicação específica na seleção de indicadores mais apropriados e matrizes mais representativas para o monitoramento biológico, como, por exemplo, a exposição ocupacional aos compostos solúveis em água de $\mathrm{Ni}$ e $\mathrm{Cr}$ que tem que ser monitorada pela amostragem da urina, enquanto que o mesmo procedimento pode não ser seguro para os compostos não solúveis em água. Além disso, a especiação do elemento dá informação adicional e essencial na avaliação da toxicidade dos metais ${ }^{8,66}$.

Um elemento traço pode estar presente numa amostra real, por exemplo, soro, sob formas físico-químicas variadas $\left(\mathrm{Pb}^{2+}, \mathrm{Pb}(\mathrm{OH})_{2}\right.$, $\mathrm{Pb}(\mathrm{OH})_{4}{ }^{2-},\left(\mathrm{CH}_{3}\right)_{4} \mathrm{~Pb},\left(\mathrm{CH}_{3} \mathrm{CH}_{2}\right)_{4} \mathrm{~Pb}$, etc...). A comunidade científica reconhece hoje que a toxicidade, biodisponibilidade e bioatividade (e, assim, o impacto biológico e ambiental do elemento tóxico) serão ditadas pela forma físico-química do elemento na amostra. Neste sentido, a determinação do elemento total, como discutido antes, é claramente insuficiente e informação adicional sobre a especiação do elemento está sendo crescentemente exigida ${ }^{67,68}$.

Numa matriz complexa como os fluidos biológicos e tecidos, alguns elementos traço ocorrem como íons livres ou mononucleares, outros como complexos de baixo peso molecular, ou como complexos macromoleculares, reversíveis ou irreversíveis. As investigações com especiação acarretam na separação dos compostos biologicamente ativos aos quais o metal está ligado, seguida da medição dos elementos traço nas diferentes frações. Atualmente, o problema é a definição dos diversos biocompartimentos onde os elementos traço são encontrados, devido às inúmeras dificuldades que podem ocorrer, tais como a complexidade da matriz, especificidade insuficiente da separação dos biocompostos, contaminações fortuitas com o elemento de interesse e a quebra da ligação original metal-proteína ${ }^{68-70}$.

\section{ANÁLISE DE ESPECIAÇÃo}

A "International Union for Pure and Applied Chemistry" (IUPAC) estabeleceu recomendações sobre o uso de terminologia comum em química, para facilitar a comunicação entre cientistas de diferentes campos e evitar interpretação errônea devido à terminologia ambígua. Assim, a IUPAC definiu a especiação como sendo a ocorrência de um elemento em diferentes formas em um sistema, e quando se referir à atividade analítica de identificar e determinar as diferentes espécies químicas em uma amostra, foi recomendado o uso do termo análise de especiação $o^{71}$.

A amostragem, o armazenamento e a manipulação da amostra são tarefas das mais difíceis na análise de especiação. O maior obstáculo nesta realização é que muitas espécies são instáveis termodinamicamente e o simples ato de coletar uma amostra e isolar a espécie de sua matriz pode alterá-la. A informação pode, então, ser irreversivelmente perdida ${ }^{72}$. Além da sua estabilidade termodinâmica, outro fator a ser levado em conta no desenvolvimento de um método para análise de especiação é a inércia cinética do seu alvo. Por isso, é de extrema importância que a escala de tempo dos métodos analíticos se equipare ao tempo real de vida da espécie em questão ${ }^{73}$.

Um dos principais desafios da especiação química em sistemas biológicos é o problema onipresente de labilidade das espécies procuradas. A necessidade de preservar a integridade das espécies a serem medidas ao longo de todo o processo analítico, desde a amostragem até a medição final, constitui a essência de tal desafio. Mudanças nas condições do meio ambiente que prevalecem nos sistemas industrial, ambiental ou biológico monitorados, freqüentemente perturbam os equilíbrios físico-químicos existentes, de tal modo que, no final, as espécies determinadas pelas medições podem não representar completamente aquelas originalmente existentes nas amostras originais ${ }^{67,73,74}$. No caso dos estudos de especiação, além de manter a integridade da ligação metal-ligante, é muito importante verificar o balanço de massa da proteína e do metal traço durante todas as etapas de separação ${ }^{75}$.

Outros desafios são as concentrações excessivamente baixas que, após o fracionamento das diferentes formas do metal, necessitarão de detectores extremamente sensíveis e seletivos para serem medidas nas análises de especiação na vida real (por exemplo, o controle de níveis de concentração de 0,001-1 $\mu \mathrm{g} \mathrm{L}^{-1}$ pode ser exigido para espécies tóxicas). Além disso, aquelas porções mínimas das espécies procuradas estão como que "enterradas" nas matrizes muito complexas (por exemplo, soro, urina, tecidos moles, etc...), típicas dos sistemas biológicos. Assim, não surpreende o fato de que, em muitas ocasiões, só um detector sensível não seja suficiente. Por esta razão, até agora, a maioria dos métodos desenvolvidos para análise de especiação geralmente envolve inúmeros processos e pré-tratamentos, colocando em risco a integridade da espécie procurada ${ }^{68,74}$.

Um importante estímulo para análise de especiação de rotina foi dado pelo "Bureau of Reference Materials" (hoje, "Measurement and Testing Program"), através de organização de numerosos proje- 
tos interlaboratoriais na última década, para melhoria e garantia da qualidade destas difíceis determinações ${ }^{67}$.

As demandas pela análise de especiação são crescentes, vindas de outras áreas, além da ambiental, tais como controle do processo industrial, indústria alimentícia, biomédica e farmacêutica. Estas considerações estão baseadas no simples fato da falta de informação fornecida pela medição do conteúdo total de metal na amostra.

Apesar do número de publicações sobre análise de especiação vir crescendo nos últimos 25 anos, os fabricantes de instrumentos ainda estão um tanto relutantes em apoiar este tipo de análise com uma linha adequada de equipamentos, por ainda se tratar, quase que exclusivamente, de assunto de pesquisa. Já o setor industrial tem sido lento em adotar as análises de especiação por medo de promover regulamentações adicionais, além da falta de instrumentação comercial. Qualquer tipo de análise, que aumente o custo total sem ter um efeito mercadológico direto, só será realizado se houver pressão suficiente por regulamentações e legislação. Entretanto, a legislação requer métodos legalmente defensáveis, que, por sua vez, geralmente são baseados em instrumentação disponível comercialmente. Contudo, as determinações das espécies metálicas deveriam ser entendidas como uma maneira de aumentar e melhorar a qualidade dos processos industriais, a um custo menor ${ }^{68,76}$.

Diante dos problemas existentes nas esferas ambiental e clínica em todo o mundo, técnicas analíticas rápidas e confiáveis são necessárias para especiação química em fluidos biológicos. A análise de especiação em materiais biológicos é hoje uma necessidade real e, também, um desafio analítico para os químicos analíticos moder$\operatorname{nos}^{67,77}$

\section{METODOLOGIAS ENVOLVIDAS NA ANÁLISE DE ESPECIAÇÃO DE FLUIDOS BIOLÓGICOS}

O desenvolvimento de vários métodos analíticos tem acompanhado o crescente interesse sobre a acumulação e toxicidade dos metais após exposição ocupacional e ambiental, possibilitando a determinação destes elementos traço em fluidos biológicos ${ }^{1,66}$.

Conforme já comentado anteriormente, a análise precisa e exata, qualitativa e quantitativa, das espécies de um elemento representa um dos trabalhos mais difíceis da química analítica. O procedimento analítico ideal deve permitir a identificação das espécies, suas determinações seletivas na amostra sob investigação e, principalmente, a preservação do estado original da ligação metal-ligante. Esta última condição é mais limitante, já que a coleta, o armazenamento e o tratamento da amostra antes da análise podem mudar a composição química da espécie sob investigação $0^{8,10}$.

Inúmeras precauções devem ser tomadas durante a coleta e o armazenamento dos fluidos biológicos, uma vez que a contaminação e as perdas do elemento traço são os maiores problemas nestas etapas. Deve-se levar em consideração que alguns fatores, tais como horário e modo de coleta, material usado na fabricação dos tubos de coleta e como anticoagulante, adição de preservativos e liofilização, também podem influenciar a especiação química de um determinado elemento nos fluidos biológicos ${ }^{72}$.

O tempo de conservação, sem que ocorram mudanças, depende do metal. No entanto, a incerteza analítica é muito grande para a maioria dos elementos, para que se possa distinguir qualquer diferença durante períodos razoáveis de armazenamento ${ }^{116}$. A centrifugação do sangue, para obtenção do plasma, é um processo que também pode levar à contaminação da amostra, como resultado da abrasão das partes giratórias da centrífuga, que freqüentemente são feitas de ligas contendo $\mathrm{Al}, \mathrm{Cd}, \mathrm{Cu}, \mathrm{Ni}$ e $\mathrm{Pb}$, e/ou a perdas do elemento, devido às altas velocidades, que retiram as plaquetas da parte líquida do sangue reduzindo, assim, a concentração de metais no soro ou plasma ${ }^{78}$.
Além de instrumentação analítica confiável, a preparação da amostra e a calibração cuidadosa são necessárias para a obtenção de resultados exatos. Processos pré-analíticos agressivos, tais como dissolução da amostra, que convertem o metal para uma forma padronizada de íon, e outros tratamentos de amostra, tais como mudanças no $\mathrm{pH}$ ou mesmo diluição, podem produzir variações químicas. Desta forma, quando fluidos biológicos estão para ser analisados, um procedimento de pré-tratamento mínimo deve ser usado para se conseguir análise rápida e exata. No entanto, é preciso ter cuidado com o tipo de composto usado para calibração $0^{10,72}$.

No caso de materiais complexos tais como metaloproteínas no plasma humano, a análise de especiação é normalmente baseada no uso combinado de diferentes e subseqüentes procedimentos analíti$\cos$, que permitem a separação quantitativa da matriz e a determinação do elemento ${ }^{117}$. Já que, em muitos casos, a especiação é referida como análise de elementos traço, as técnicas analíticas usadas devem unir seletividade específica (individualização e caracterização da espécie do elemento) à alta sensibilidade (determinações de $\mathrm{ppb}$ ou ppt $)^{75,79}$.

Várias técnicas de separação são empregadas para pré-concentrar ou isolar uma forma química específica na obtenção de um produto final, onde as espécies possam ser determinadas quantitativamente. Os métodos cromatográficos, entre eles a cromatografia gasosa, líquida de alta resolução (HPLC), troca iônica, exclusão de tamanho (SEC), são muito úteis na identificação simultânea de diferentes espécies. Outras técnicas de separação também são utilizadas, tais como ultrafiltração, ultracentrifugação, extração com solvente, destilação, pirólise e outras ${ }^{1,10,69,77}$.

Diversas técnicas de detecção são usadas para determinar os elementos nas frações da amostra, previamente separadas da matriz sob investigação. Entre elas, as mais usadas são a espectrometria de absorção atômica, com diferentes atomizadores tais como forno de grafite (ET AAS), chama (FAAS), vapor frio (CVAAS) e geração de hidretos (HGAAS); de emissão ótica (ICP OES) ou de massa (ICP MS); voltametria nas suas diferentes formas (polarografia de pulso diferencial, voltametria de redissolução anódica, eletrodo de íon seletivo); análise por ativação de neutrons (NAA), análise por ativação radioquímica de neutrons (RNAA) e outros ${ }^{1,8,70,79}$. A escolha de uma determinada técnica depende principalmente da acuracidade e sensibilidade necessárias, da matriz da amostra, do elemento de interesse e dos custos ${ }^{1}$

Até o final da década passada, as técnicas mais utilizadas para a determinação das espécies metálicas em fluidos biológicos eram ET AAS $>$ CVAAS $>$ HGAAS $>$ FAAS $>$ ICP OES $>$ ICP MS. Atualmente a espectrometria de absorção atômica está sofrendo forte concorrência da espectrometria de massas com plasma indutivamente acoplado (ICP MS), que vem ganhando popularidade devido à sua capacidade multi-elementar, baixos limites de detecção $\left(\right.$ ng L $\left.^{-1}\right)$ e à possibilidade de diluição isotópica "on line". Entretanto, seu uso tem sido dificultado pelos custos elevados de instrumentação e de manutenção ${ }^{10}$.

As técnicas de espectrometria atômica são muito sensíveis e seletivas para a determinação de metais, e particularmente atrativas para os estudos de especiação, uma vez que a maioria dos laboratórios envolvidos com monitoramento tem um equipamento de absorção atômica disponível. No entanto, sozinhas não são adequadas para a determinação in situ das espécies metálicas, uma vez que o pequeno tempo de residência no caminho ótico e a elevada temperatura dos atomizadores podem criar problemas para diferenciar as diferentes formas químicas do analito. Neste sentido, a estratégia para a utilização da espectrometria atômica na análise de especiação é a sua hifenização com as técnicas de separação ${ }^{10}$.

Técnicas hifenadas são aquelas que, combinando a separação e a análise quantitativa, permitem a determinação simultânea de espéci- 
es específicas numa determinada amostra. Na análise de especiação, as técnicas de acoplamento direto levam a resultados reprodutivos com menor risco de contaminação ou perdas do analito em um curto período de tempo. As diversas possibilidades de hifenação de uma técnica de separação com um detector específico para análise de especiação bioinorgânica incluem diferentes tipos de cromatografia líquida ou eletroforese para separação, e espectrometria atômica ou de massa para detecção $0^{77,80}$.

Um problema importante é a interface entre a cromatografia e a espectrometria, já que as condições de separação podem não ser compatíveis em termos de fluxo e composição da fase móvel com aquelas exigidas pelo detector. Geralmente, cromatografia e espectrometria podem ser acopladas "on line". No entanto, a preferência por uma técnica de atomização discreta e altamente sensível como a ET AAS ou ETV ICP MS pode ser a razão para a escolha do método de acoplamento "off line"

Experiências interessantes têm sido realizadas acoplando HPLC com FAAS, HGAAS, ET AAS, ICP OES ou ICP MS M $^{1,8,10,80}$. Este último conjunto (HPLC/ICP MS) tem também a vantagem de ser um sistema de especiação em linha no tempo real. Esse acoplamento tem grande potencialidade, porém sua transferência para matrizes biológicas exige um comprometimento prático entre os procedimentos de separação e o desempenho dos detectores. Por outro lado, compromissos adicionais podem ser necessários para reduzir os custos de análise, que estão relacionados com a duração das colunas cromatográficas, dispositivos e acessórios do ICP MS, tempo de análise e outros ${ }^{77,79}$.

Como a análise de especiação de metais traço é relativamente recente e extremamente complexa, o número de revisões sobre o assunto tem sido crescente. Algumas são gerais, enquanto outras se concentram na análise de especiação de determinados analitos ou nas técnicas utilizadas para separação e detecção ${ }^{80-83}$. Alguns pesquisadores utilizaram-se da interface entre HPLC e ICP MS para separar e quantificar as espécies metálicas existentes em amostras biológicas $^{84}$. Os mecanismos de separação mais utilizados nestas análises incluem a cromatografia por exclusão de tamanho ${ }^{85,86}$, de fase reversa ${ }^{87}$ e de troca iônica ${ }^{84,88}$, e a eletroforese capilar ${ }^{82,89}$. A separação das proteínas nos fluidos biológicos através da cromatografia líquida de baixa pressão por exclusão de tamanho e detecção dos metais pela espectrometria de massas com plasma indutivamente acoplado também têm sido muito estudadas ${ }^{85,88,90}$. Após a separação deste tipo de amostra, outras hifenizações utilizadas incluem a determinação dos analitos por espectrometria de emissão ótica com plasma indutivamente acoplado (ICP OES) ${ }^{91}$.

As espécies de alumínio e silício no soro humano foram separadas por cromatografia de troca iônica de alta resolução e os elementos de interesse, quantificados por espectrometria de absorção atômica eletrotérmica ${ }^{92}$. Favarato e colaboradores identificaram um novo carreador de alumínio no soro humano, através da cromatografia por exclusão de tamanho de alta resolução e posterior determinação do metal por ET AAS ${ }^{93}$. Este mesmo acoplamento também permitiu a análise de especiação de $\mathrm{Pb}$ e $\mathrm{Pt}$ em amostras biológicas ${ }^{94}$, de $\mathrm{Cu}$ em leite humano ${ }^{95}$ e As nas células vermelhas do sangue ${ }^{96}$. Uma técnica híbrida entre HPLC e ET AAS foi desenvolvida para estudar a ligação de proteínas com $\mathrm{Al}$ e $\mathrm{Fe}^{97}$ e determinar as espécies de Pt no plasma $^{98}$. Um sistema consistindo de cromatografia de fase reversa e ET AAS permitiu a determinação das espécies de As e Se encontradas no ambiente e em mamíferos ${ }^{99}$, enquanto que a ligação de metais às proteínas do sangue foi investigada empregando a cromatografia de interação hidrofóbica para a separação de proteínas e a detecção do elemento por ET AAS ${ }^{100}$. Os complexos de magnésio com proteínas do soro humano foram separados por meio de uma coluna de troca iônica e o metal quantificado por ET $\mathrm{AAS}^{101}$. A cromatografia por exclusão de tamanho e a espectrometria de absorção atômica na chama foram usadas para a determinação das espécies metálicas existentes no soro do leite ${ }^{102}$.

A hifenização da cromatografia líquida de alta resolução com a espectrometria de absorção atômica por geração de hidretos (HG AAS) permitiu a análise de especiação de arsênio na urina ${ }^{103}$. Também a cromatografia de troca iônica foi empregada para a separação das espécies de As na urina e no soro ${ }^{104}$.

A especiação exige um tratamento substancialmente diferente e tem que ser seletivamente desempenhada para aquela espécie metálica naquela amostra, já que nenhum método proporciona uma identificação universal e inequívoca de espécies em todas as condições ${ }^{69}$.

\section{CONSIDERAÇÕES FINAIS}

O término das exposições ao chumbo é muito difícil a curto e médio prazos. No entanto, esforços devem ser concentrados para localizar as populações de risco e, assim, interferir no processo de contaminação. Medidas preventivas e corretivas podem ser adotadas para diminuir a utilização do chumbo e, conseqüentemente, sua exposição. Dentre elas, estão a remoção do chumbo de aditivos, tintas, vasilhas para armazenamento de alimentos, cosméticos e medicamentos; melhor identificação da população sob risco; educação populacional em procedimentos preventivos; promoção de programas que visem a diminuição da desnutrição e de outros fatores que agravem a intoxicação ao chumbo e melhor controle dos locais de trabalho, através de fiscalizações mais sérias, entre outras. Por outro lado, a legislação brasileira tem que ser aperfeiçoada, no sentido de introduzir novos parâmetros e atualizar outros, para que possa efetivamente servir de base para as intervenções e garantir um controle da exposição dos trabalhadores e da população em geral, em níveis que não comprometam sua saúde.

Como alguns dos mecanismos controladores dos processos fisiológicos (absorção, distribuição e eliminação do chumbo) continuam desconhecidos, muitas pesquisas ainda precisam ser desenvolvidas na tentativa de esclarecer os reais ligantes e mecanismos de ação do chumbo, que permanecem obscuros. O plasma sangüíneo contém a fração biodisponível do analito e pode intermediar a predição de algumas formas crônicas de toxicidade. Entretanto, nem todas as espécies de chumbo existentes no plasma são conhecidas. Portanto, a especiação, ou seja, a caracterização dos constituintes que se ligam e/ou que transportam o elemento de interesse é fundamental para total entendimento do metabolismo, elucidação dos mecanismos de toxicidade, melhor compreensão da distribuição do chumbo na célula, ou ainda para o estudo das interações do metal com as proteínas e sua deposição nos tecidos.

A análise de especiação é extremamente complexa, visto que exige cuidados excessivos em todos os procedimentos executados, desde a amostragem até a medição final. Amostragem, armazenamento e manipulação da amostra são tarefas difíceis, e a estabilidade termodinâmica e a inércia cinética das espécies procuradas são grandes obstáculos. Também, a necessidade de preservar a integridade das espécies a serem medidas ao longo de todo o processo analítico constitui a essência do desafio da especiação química em sistemas biológicos.

Embora outras técnicas de separação sejam utilizadas, os métodos cromatográficos são muito úteis na identificação simultânea das diferentes espécies e as técnicas mais usadas para a determinação dos metais nestas frações são a espectrometria de massa com plasma indutivamente acoplado e de absorção atômica.

A percepção da série de eventos entre a exposição ao chumbo e as alterações biológicas, que levam aos efeitos adversos, é fundamental para o desenvolvimento de métodos relevantes de monitora- 
mento biológico. Especificamente, os estudos de novos modelos biológicos, tais como a especiação química, que além de fornecer base para melhor compreensão dos mecanismos de ação do chumbo no organismo, serão de grande utilidade na avaliação dos efeitos tóxicos observados em populações expostas ao metal em questão.

Assim, é preciso um entendimento melhor da relação entre o chumbo e suas espécies e os efeitos sobre a saúde humana, de modo que possa ocorrer uma avaliação de risco mais exata. Esta melhor compreensão requer uma coleta consistente de dados e procedimentos de análise que considerem as diferentes espécies do chumbo. A análise de especiação do chumbo no plasma é essencial para identificar as espécies formadas, entender e estimar os mecanismos de interação entre o analito e seus alvos biológicos e, conseqüentemente, calcular mais acuradamente os riscos à saúde.

\section{REFERENCIAS}

1. D’Haese, P. C.; Van Landeghem, G. F.; Lamberts, L. V.; DeBroe, M. E.; Mikrochim. Acta 1995, 120, 83

2. Xie, Y.; Chiba, M.; Shinohara, A.; Watanabe, H.; Inaba, Y.; Ind. Health 1998, 36, 234.

3. Sanín, L. H.; Cossío, T. G.; Romieu, I.; Avila, M. H.; Salud Pública Mex. 1998, 40, 359; Smith, R. D.; Osterloh, J. D.; Flegal, A. R.; Environ. Health Perspect. 1996, 104, 60; Elinder, C. G.; Friberg, L.; Kjellström, T.; Nordberg, G.; Oberdoerster, G.; Biological Monitoring of Metals, Environmental Epidemiology - Office of Global and Integrated Environmental Health - World Health Organization: Geneva, 1994.

4. Tsaih, S. W.; Schwartz, J.; Lee, M. L. T.; Amarasiriwardena, C.; Aro, A.; Sparrow, D.; Hu, H.; Environ. Health Perspect. 1999, 107, 391.

5. Agency for Toxic Substances and Disease Registry; Toxicological Profile for Lead, Public Health Service - US Department of Health and Human Services: Atlanta, 1999.

6. Tsalev, D. L.; Zaprianov, Z. K.; Atomic Absorption Spectrometry in Occupational and Environmental Health Practice, $2^{\text {nd }}$ ed., CRC Press: Boca Raton, 1985, vol. I.

7. International Programme on Chemical Safety; Environmental Health Criteria 165 - Inorganic Lead, World Health Organization: Geneva, 1995.

8. Apostoli, P.; Med. Lav. 1998, 89, 3.

9. Das, A. K.; Chakraborty, R.; Fresenius J. Anal. Chem. 1997, 357, 1.

10. Das, A. K.; Chakraborty, R.; Cervera, M. L.; Guardia, M.; Mikrochim. Acta 1996, 122, 209.

11. Hirata, M.; Yoshida, T.; Miyajima, K.; Kosaka, H.; Tabuchi, T.; Int. Arch. Occup. Environ. Health 1995, 68, 58; Bergdahl, I. A.; Schutz, A.; Gerhardsson, L.; Jensen, A.; Skerfving, S.; Scand. J. Work Environ. Health 1997, 23, 359.

12. Ohweiler, O. A.; Química Inorgânica, Ed. Blucher: São Paulo, 1971, vol.1.

13. Alessio, L.; Foà, V.; Human Biological Monitoring of Industrial Chemicals Series - Lead, CCE: Luxembourg, 1983.

14. Saryan, L. A.; Zenz, C.; Occupational Medicine, $3^{\text {rd }}$ ed., Mosby - Year Book: St. Louis, 1994, cap. 38.

15. Agency for Toxic Substances and Disease Registry; Case Studies in Environmental Medicine - Lead Toxicity, Public Health Service - US Department of Health and Human Services: Atlanta, 1992.

16. $\mathrm{h} \mathrm{t} \mathrm{t} \mathrm{p}: / / \mathrm{b}$ o a s a $\mathrm{u}$ d e. u o l. c o m. b r / $1 \mathrm{i}$ b / ShowDoc.cfm?LibDocID=3859\&ReturnCatID=1773, acessada em Junho 2003.

17. Romieu, I.; Lacasana, M.; McConnell, R.; Environ. Health Perspect. 1997, $105,398$.

18. Cordeiro, R.; Tese de Doutorado, Universidade Estadual de Campinas, Brasil, 1995.

19. http://www.estado.estadao.com.br/editorias/2002/04/11/ger016.html, acessada em Junho 2003

20. http://www.estadao.com.br/ciencia/noticias/2001/out/31/38.htm, acessada em Junho 2003.

21. http://www.geoamb.eng.ufba.br/rperigosos.htm, acessada em Junho 2003.

22. http://www.jt.estadao.com.br/editorias/2001/08/24/ger027.html, acessada em Junho 2003.

23. http://www.greenpeace.org.br/toxicos/Chumbo_Grosso.doc, acessada em Junho 2003.

24. Quitério, S. L.; Silva, C. R. S.; Arbilla, G.; Moreira, M. F. R.; Araújo, U. C.; Mattos, R. C. O. C.; Santos, L. S. C. ; Cad. Saúde Pública 2003, 19, 475.

25. Cordeiro, R.; Lima Filho, E. C.; Salgado, P. E. T.; Rev. Saúde Pública 1996, $30,248$.
26. Haber, L. T.; Maier, A.; Regul. Toxicol. Pharm. 2002, 36, 262.

27. Araújo, U. C.; Pivetta, F. R.; Moreira, J. C.; Cad. Saúde Pública 1999, $15,123$.

28. Rothenberg, S. J.; Karchmer, S.; Schnaas, L.; Perroni, E.; Zea, F.; Fernandez, A. J.; Environ. Health Perspect. 1994, 102, 876; Gulson, B. L.; Mahaffey, K. R.; Vidal, M.; Jameson, C. W.; Law, A. J.; Mizon, K. J.; Smitjh, A. J.; Korsch, M. J.; Environ. Health Perspect. 1997, 105, 1334.

29. Baghurst, P. A.; McMichael, A. J.; Vimpani, G. V.; Robertson, E. F.; Clark, P. D.; Wigg, N. R.; Med. J. Australia 1987, 146, 69; Cheng, Y.; Willett, W. C.; Schwartz, J.; Sparrow, D.; Weiss, S.; Hu, H.; Am. J. Epidemiol. 1998, 147, 1162; Farias, P.; Borja-Aburto, V. H.; Rios, C.; Hertz-Picciotto, I.; RojasLopez, M.; Chavez-Ayala, R.; Environ. Health Perspect. 1996, 104, 1070.

30. Rabinowitz, M. B.; Wetherill, G. W.; Kopple, J. D.; J. Clin. Invest. 1976, $58,260$.

31. Hu, H.; Environ. Health Perspect. 1998, 106, 961.

32. Smith, R. D.; Osterloh, J. D.; Flegal, A. R.; Environ. Health Perspect. 1996, 104, 60; Gulson, B. L.; Mahaffey, K. R.; Mizon, K. J.; Korsch, M. J.; Cameron, M. A.; Vimpani, G.; J. Lab. Clin. Med. 1995, 125, 703.

33. Goyer, R. A; Casareh and Doull's Toxicology - The Basic Science of Poisons, $4^{\text {th }}$ ed., Pergamon Press: New York, 1991, cap. 19.

34. Skerfving, S.; Criteria Documents from the Nordic Expert Group for Documentation for Occupational Exposure Limits, Arbete \& Hälsa: Stockholm, 1993, vol. 1.

35. Nashashibi, N.; Cardamakis, E.; Bolbos, G.; Tzingounis, V.; Gynecol. Obstet. Invest. 1999, 48, 158.

36. Kim, R.; Hu, H.; Rotnitzky, A.; Bellinger, D.; Needleman, H.; Arch. Environ. Health 1996, 51, 375.

37. Gulson, B. L.; Pounds, J. G.; Mushak, P.; Thomas, B. J.; Gray, B.; Korsch, M. J.; J. Lab. Clin. Med. 1999, 134, 631.

38. Silbergeld, E. K.; Environ. Health Perspect. 1991, 91, 63.

39. Roberts, J. S.; Silbergeld, E. K.; Mount Sinai J. Med. 1995, 62, 343; Pires, B. J.; Bezerra, F. F.; Laboissiere, F. P.; Miekeley, N.; Donangelo, C. M.; Nutr. Res. 2001, 21, 831.

40. Rust, S. W.; Burgoon, D. A.; Niemuth, N. A.; Schultz, B. D.; Environ. Res. 1999, 81, 175; Gulson, B. L.; Gray, B.; Mahaffey, K. R.; Jameson, C. W.; Mizon, K. J.; Patison, N.; Korsch, M. J.; J. Lab. Clin. Med. 1999, 133, 171.

41. Hertz-Picciotto, I.; Schramm, M.; Watt-Morse, M.; Chantala, K.; Anderson, J.; Osterloh, J.; Am. J. Epidemiol. 2000, 152, 829.

42. Tellez-Rojo, M. M.; Hernandez-Avila, M.; Gonzalez-Cossio, T.; Romieu, I.; Aro, A.; Palazuelos, E.; Schwartz, J.; Hu, H.; Am. J. Epidemiol. 2002, 155,420 .

43. Silbergeld, E. K; Schwartz, J.; Mahaffey, K.; Environ. Res. 1988, 47, 79; Weyermann, M.; Brenner, H.; Environ. Res. 1998, 76, 19.

44. Hernandez-Avila, M.; Villalpando, C. G.; Palazuelos, E.; Hu, H.; Villalpando, M. E. G.; Martinez, D. R.; Arch. Environ. Health 2000, 55, 355; Symanski, E.; Hertz-Picciotto, I.; Am. J. Epidemiol. 1995, 141, 1047.

45. Webber, C. E.; Chettle, D. R.; Bowins, R. J.; Beaumont, L. F.; Gordon, C. L.; Song, X.; Blake, J. M.; McNutt, R. H.; Environ. Health Perspect. 1995, $103,1150$.

46. Goldman, R. H.; White, R.; Kales, S. N.; Hu, H.; Am. J. Ind. Med. 1994, 25, 417; Osterode, W.; Zettinig, G.; Potzi, C.; Manner, G.; J. Toxicol. Environ. Health, Part A 2002, 65, 649.

47. Aufderheide, A. C.; Wittmers, L. E. Jr.; Neurotoxicol. 1992, 13, 809.

48. Tell, I.; Somervaille, L. J.; Nilsson, U.; Bensryd, I.; Schutz, A.; Chettle, D. R.; Scott, M. C.; Skerfving, S.; Scand. J. Work Environ. Health 1992, 18, 113; Gerhardsson, L.; Borjesson, J.; Mattsson, S.; Schutz, A.; Skerfving, S.; Environ. Res. 1999, 80, 389; Hu, H.; Pepper, L.; Goldman, R.; Am. J. Ind. Med. 1991, 20, 723.

49. Gulson, B. L.; Jameson, C. W.; Mahaffey, K. R.; Mizon, K. J.; Patison, N.; Law, A. J.; Korsch, M. J.; Salter, M. A.; Environ. Health Perspect. 1998, $106,667$.

50. Osterberg, K.; Borjesson, J.; Gerhardsson, L.; Schutz, A.; Skerfving, S.; Sci. Total Environ. 1997, 201, 39; Hanninen, H.; Aitio, A.; Kovala, T.; Luukkonen, R.; Matikainen, E.; Mannelin, T.; Erkkila, J.; Riihimaki, V.; Occup. Environ. Med. 1998, 55, 202; Schwartz, B. S.; Stewart, W. F.; Bolla, K. I.; Simon, P. D.; Bandeen-Roche, K.; Gordon, P. B.; Links, J. M.; Todd, A. C.; Neurol. 2000, 55, 1144.

51. Nordberg, M.; Winblad, B.; Fratiglioni, L.; Basun, H.; Am. J. Ind. Med. 2000, 38, 290.

52. Murata, K.; Araki, S.; Yokoyama, K.; Uchida, E.; Fujimura, Y.; Environ. Res. 1993, 61, 323; Hirata, M.; Kosaka, H.; Environ. Res. 1993, 63, 60; Murata, K.; Araki, S.; Yokoyama, K.; Nomiyama, K.; Nomiyama, H.; Tão, Y. X.; Liu, S. J.; Am. J. Ind. Med. 1995, 28, 233; Araki, S.; Sato, H.; Yokoyama, K.; Murata, K.; Am. J. Ind. Med. 2000, 37, 193; Kovala, T.; Matikainen, E.; Mannelin, T.; Erkkila, J.; Riihimaki, V.; Hanninen, H.; Aitio, A.; Occup. Environ. Med. 1997, 54, 487. 
53. Hu, H.; Watanabe, H.; Payton, M.; Korrick, S.; Rotnitzky, A.; JAMA 1994, 272, 1512; Serwint, J. R.; Damokosh, A. I.; Berger, O. G.; Chisolm, J. J. Jr.; Gunter, E. W.; Jones, R. L.; Rhoads, G. G.; Rogan, W.; J. Pediatr. 1999, 135, 108; Wright, R. O.; Curr. Opin. Pediatr. 1999, 11, 255; Osterode, W.; Barnas, U.; Geissler, K.; Occup. Environ. Med. 1999, 56, 106; Counter, S. A.; Buchanan, L. H.; Ortega, F.; Rifai, N.; Neurotoxicol. 2000, 21, 301; Suplido, M. L.; Ong, C. N.; Environ. Res. 2000, 82, 231; Vahter, M.; Counter, S. A.; Laurell, G.; Buchanan, L. H.; Ortega, F.; Schutz, A.; Skerfving, S.; Int. Arch. Occup. Environ. Health 1997, 70, 282; Froom, P.; Kristal-Boneh, E.; Benbassat, J.; Ashkanazi, R.; Ribak, J.; J. Occup. Environ. Med. 1999, 41, 120.

54. Koo, W. W.; Succop, P. A.; Bornschein, R. L.; Krug-Wispe, S. K.; Steinchen, J. J.; Tsang, R. C.; Berger, O. G.; Pediatr. 1991, 87, 680; Singh, B.; Chandran, V.; Bandhu, H. K.; Mittal, B. R.; Bhattacharya, A.; Jindal. S. K.; Varma, S.; Biometals 2000, 13, 187; Erfurth, E. M.; Gerhardsson, L.; Nilsson, A.; Rylander, L.; Schutz, A.; Skerfving, S.; Borjesson, J.; Arch. Environ. Health 2001, 56, 449.

55. Berglund, M.; Akesson, A.; Bjellerup, P.; Vahter, M.; Toxicol. Lett. 2000, 15, 112; Berglund, M.; Akesson, A.; Bjellerup, P.; Vahter, M.; Toxicol. Lett. 2000, 15, 219; Ballew, C.; Khan, L. K.; Kaufmann, R.; Mokdad, A.; Miller, D. T.; Gunter, E. W.; J. Pediatr. 1999, 134, 623; Vivoli, G.; Fantuzzi, G.; Bergomi, M.; Tonelli, E.; Gatto, M. R.; Zanetti, F.; Del Dot, M.; J. Exp. Anal. Environ. Epidemiol. 1993, 3, 201; Hicks, D. G.; O’Keefe, R. J.; Reynolds, K. J.; Cory-Slechta, D. A.; Puzas, J. E.; Judkins. A.; Rosier, R. N.; Toxicol. Appl. Pharmacol. 1996, 140, 164.

56. Loghman-Adham, M.; Environ. Health Perspect. 1997, 105, 928; Nolan, C. V.; Shaikh, Z. A.; Toxicology 1992, 73, 127.

57. Lee, B. K.; Lee, G. S.; Stewart, W. F.; Ahn, K. D.; Simon, D.; Kelsey, K. T.; Todd, A. C.; Schwartz, B. S.; Environ. Health Perspect. 2001, 109, 383.

58. Paksy, K.; Gati, I.; Naray, M.; Rajczy, K.; J. Toxicol. Environ. Health 2001, 62, 359; Marchlewicz, M.; Ann. Acad. Med. Stetin. 1994, 40, 37; Flora, G. J.; Arora, U.; Seth, P. K.; Biomed. Environ. Sci. 1999, 12, 285; Gandley, R.; Anderson, L.; Silbergeld, E. K.; Environ. Res. 1999, 80, 355; Alexander, B. H.; Checkoway, H.; Costa-Mallen, P.; Faustman, E. M.; Woods, J. S.; Kelsey, K. T.; Netten, C.; Costa, L. G.; Environ. Health Perspect. 1998, 106, 213; Han, S. G.; Pfizenmaier, D. H.; Garcia, E.; Eguez, M. L.; Ling, M.; Kemp, F. W.; Bogden, J. D.; Environ. Health Perspect. 2000, 108, 527; Andrews, K. W.; Savitz, D. A.; Hertz-Picciotto, I.; Am. J. Ind. Med. 1994, 26, 13; Odland, J. O.; Nieboer, E.; Romanova, N.; Thomassen, Y.; Lund, E.; Act. Obstetr. Gynecol. Scandin. 1999, 78, 852; Sanchéz, L. E. T.; Berkowitz, G.; Carrillo, L. L.; Arreola, L. T.; Rios, C.; Cervantes, M. C.; Environ. Res. 1999, 81, 297.

59. http://www.atsdr.cdc.gov/cxcx3.html, acessada em Agosto 2002; Silbergeld, E. K.; Waalkes, M.; Rice, J. M.; Am. J. Ind. Med. 2000, 38, 316.

60. Victery, W.; Tyroler, H. A.; Volpe, R.; Grant, L. D.; Environ. Health Perspect. 1988, 78, 139; Dolenc, P.; Staessen, J. A.; Lauwerys, R. R.; Amery, A.; J. Hypertens. 1993, 11, 589.

61. Hsiao, C. Y.; Wu, H. D.; Lai, J. S.; Kuo, H. W.; Sci. Total Environ. 2001, $279,151$.

62. http://www.oehha.org/air/hot_spots/HRSguide.html, acessada em Outubro 2002.

63. Pivetta, F.; Machado, J. M. H.; Araújo, U. C.; Moreira, M. F. R.; Apostoli, P.; Cad. Saúde Pública 2001, 17, 545.

64. Todd, A. C.; Carroll, S.; Geraghty, C.; Khan, F. A.; Moshier, E. L.; Tang, S.; Parsons, P. J.; Phys. Med. Biol. 2002, 47, 1399.

65. Smith, D.; Hernandez-Avila, M.; Tellez-Rojo, M. M.; Mercado, A.; Hu, H.; Environ. Health Perspect. 2002, 110, 263.

66. Van Loon, J.; Barefoot, R. R.; Analyst 1992, 117, 563.

67. Sanz-Medel, A.; Analyst 1995, 120, 799.

68. Donard, O. F. X.; Caruso, J. A.; Spectrochim. Acta, Part B 1998, 53, 157.

69. Das, A. K.; Chakraborty, R.; Cervera, M. L.; Guardia, M.; Talanta 1995, 42, 1007; Cornelis, R.; Heinzow, B.; Herber, R. F. M.; Christensen, J. M.; Poulsen, O. M.; Sabbioni, E.; Templeton, D. M.; Thomassen, O. M.; Vahter, M.; Vesterberg, O.; J. Trace Elements Med. Biol. 1996, 10, 103.

70. Cornelis, R.; Dekimpe, J.; J. Anal. At. Spectrom. 1994, 9, 945.

71. http://www.iupac.org/publications/pac/2000/7208/7208pdfs/ 7208templeton_1453.pdf, acessada em Maio 2003.

72. Cornelis, R.; De Kimpe, J.; Zhang, X.; Spectrochim. Acta, Part B 1998 , $53,187$.

73. Lobinski, R.; Spectrochim. Acta, Part B 1998, 53, 177.

74. Sanz-Medel, A.; Spectrochim. Acta, Part B 1998, 53, 197.

75. Cornelis, R.; Borguet, F.; Dekimpe, J.; Anal. Chim. Acta 1993, 283, 183.

76. Welz, B.; Spectrochim. Acta, Part B 1998, 53, 169.

77. Dunemann, L.; Fresenius J. Anal. Chem. 1992, 342, 802.
78. Pineau, A.; Guillard, O.; Chappuis, P.; Arnaud, J.; Zawislak, R.; Crit. Rev. Clin. Lab. Sci. 1993, 30, 203.

79. Lobinski, R.; Appl. Spectrosc. 1997, 51, 260

80. Szpunar, J.; Analyst 2000, 125, 963.

81. Ellis, L. A.; Roberts, D. J.; J. Chromatogr., A 1997, 774, 3; Sarzanini, C.; J. Chromatogr., A 1999, 850, 213; Lobinski, R.; Szpunar, J.; Anal. Chim. Acta 1999, 400, 321; De La Guardia, M.; Cervera, M. L.; Morales-Rubio, A.; Adv. At. Spectrosc. 1999, 5, 1; Evans, E. H.; Dawson, J. B.; Fisher, A.; Hill, S. J.; Price, W. J.; Smith, C. M. M.; Sutton, K. L.; Tyson, J. F.; J. Anal. At. Spectrom. 2001, 16, 672; Montes-Bayón, M.; DeNicola, K.; Caruso, J. A.; J. Chromatogr., A 2003, 1000, 457.

82. Timerbaev, A. R.; Anal. Chim. Acta 2001, 433, 165; Kannamkumarath, S. S.; Wrobel, K.; Wrobel, K.; B'Hymer, C.; Caruso, J. A.; J. Chromatogr., A 2002, 975, 245; Majidi, V.; Microchem. J. 2000, 66, 3.

83. Sanz-Medel, A.; Cabezuelo, A. B.; Milacic, R.; Polak, T. B.; Coord. Chem. Rev. 2002, 228, 373; van Landeghem, G. F.; De Broe, M. E.; D’Haese, P. C.; Clin. Biochem. 1998, 31, 385.

84. Byrdy, F. A.; Caruso, J. A.; Environ. Health Perspect. 1995, 103, 21; Soldado Cabezuelo, A. B.; Montes Bayon, M.; Blancon Gonzalez, E.; Garcia Alonso, J. I.; Sanz-Medel, A.; Analyst 1998, 123, 821; Bergdahl, I. A.; Grubb, A.; Schutz, A.; Desnick, R. J.; Wetmur, J. G.; Sassa, S.; Skerfving, S.; Pharmacol. Toxicol. 1997, 123, 13.

85. Bratter, P.; Blasco, I. N.; Negretti de Bratter, V. E.; Raab, A.; Analyst 1998, 123,865 .

86. Makarov, A.; Szpunar, J.; Analusis 1998, 26, M 44; Szpunar, J.; Makarov, A.; Pieper, T.; Keppler, B. K.; Lobinski, R.; Anal. Chim. Acta 1999, 387, 135; Mason, A. Z.; Storms, S. D.; Jenkins, K. D.; Anal. Biochem. 1990, $186,187$.

87. Chassaigne, H.; Szpunar, J.; Analusis 1998, 26, M 48.

88. Shum, S. C. K.; Houk, R. S.; Anal. Chem. 1993, 65, 2972.

89. Michalke, B.; Schramel, P.; Analusis 1998, 26, M 51.

90. Gerken, B.; Barnes, R. M.; Anal. Chem. 1991, 63, 283; Wang, J.; Houk, R. S.; Dressen, D.; Wiederin, D. R.; J. Biol. Inorg. Chem. 1999, 4, 546; Inagaki, K.; Mikuriya, N.; Morita, S.; Haraguchi, H.; Nakahara, Y.; Kinosita, T.; Saito, H.; Analyst 2000, 125, 197; Wang, J.; Houk, R. S.; Dreessen, D.; Wiederin, D. R.; J. Am. Chem. Soc. 1998, 120, 5793.

91. Bocca, B.; Alimonti, A.; Coni, E.; Di Pasquale, M.; Giglio, L.; Piccioli Bocca, A.; Caroli, S.; Talanta 2000, 53, 295; Pomazal, K.; Prohaska, C.; Steffan, I.; Reich, G.; Huber, J. F. K.; Analyst 1999, 124, 657; Wolf, C.; Rosick, U.; Bratter, P.; Fresenius J. Anal. Chem. 2000, 368, 839.

92. Soldado Cabezuelo, A. B.; Blanco Gonzalez, E.; Sanz-Medel, A.; Analyst 1997, 122, 573; Wrobel, K.; Blanco Gonzalez, E.; Wrobel, K.; Sanz-Medel, A.; Analyst 1995, 120, 809; Polak, T. B.; Milacic, R.; Mitrovic, B.; Benedik, M.; J. Pharm. Biomed. Anal. 2001, 26, 189.

93. Favarato, M.; Mizzen, C. A.; McLachlan, D. R.; J. Chromatogr. 1992, 576, 271

94. Scancar, J.; Milacic, R.; Falnoga, I.; Cemazar, M.; Bukovec, P.; J. Pharm. Biomed. Anal. 2000, 22, 993.

95. Bermejo, P.; Pena, E.; Fompedrina, D.; Dominguez, R.; Bermejo, A.; Fraga, J. M.; Cocho, J. A.; Analyst 2001, 126, 571

96. Gailer, J.; Lindner, W.; J. Chromatogr., B: Biomed. Sci. Appl. 1998, 716, 83.

97. van Landeghem, G. F.; D’Haese, P. C.; Lamberts, L. V.; De Broe, M. E.; Anal. Chem. 1994, 66, 216.

98. Verschraagen, M.; van Der Born, K.; Zwiers, T. H.; van Der Vijgh, W. J.; J. Chromatogr., B: Biomed. Sci Appl. 2002, 772, 273; Hanada, K.; Nishijima, K.; Ogata, H.; Atagi, S.; Kawahara, M.; Jpn. J. Clin. Oncol. 2001, 31, 179 .

99. Do, B.; Robinet, S.; Pradeau, D.; Guyon, F.; J. Chromatogr., A 2001, 918, 87.

100. Pomazal, K.; Prohaska, C.; Steffan, L.; J. Chromatogr., A 2002, 960, 143.

101. Godlewska-Zylkiewicz, B.; Lesniewska, B.; Hulanicki, A.; Anal. Chim. Acta 1998, 358, 185.

102. Bermejo, P.; Pena, E.; Fompedrina, D.; Dominguez, R.; Bermejo, A.; Cocho, J. A.; Fernandez, J. R.; Fraga, J. M.; J. AOAC Int. 2001, 84, 847.

103. Tseng, W. C.; Yang, M. H.; Chen, T. P.; Huang, Y. L.; Analyst 2002, 127, 560; Hsueh, Y. M.; Hsu, M. K.; Chiou, H. Y.; Yang, M. H.; Huang, C. C.; Chen, C. J.; Toxicol. Lett. 2002, 133, 83; Tsalev, D. L.; Sperling, M.; Welz, B.; Analyst 1998, 123, 1703; Hwang, Y. H.; Lee, Z. Y.; Wang, J. D.; Hsueh, Y. M.; Lu, I. C.; Yao, W. L.; Environ. Res. 2002, 90, 207.

104. Heinrich-Ramm, R.; Mindt-Prufert, S.; Szadkowski, D.; Int. J. Hyg. Environ. Health 2001, 203, 475; Zhang, X.; Cornelis, R.; Mees, L.; Vanholder, R.; Lameire, N.; Analyst 1998, 123, 13. 